\title{
Analyzing Fault Reactivation Potential of CO2 Storage
}

\section{*Ogochukwu Ozotta, Mehdi Ostadhassan, Kouqi Liu}

*ogochukwu.ozotta@und.edu 
U.S Annual emission rate (Ib/Mwh)

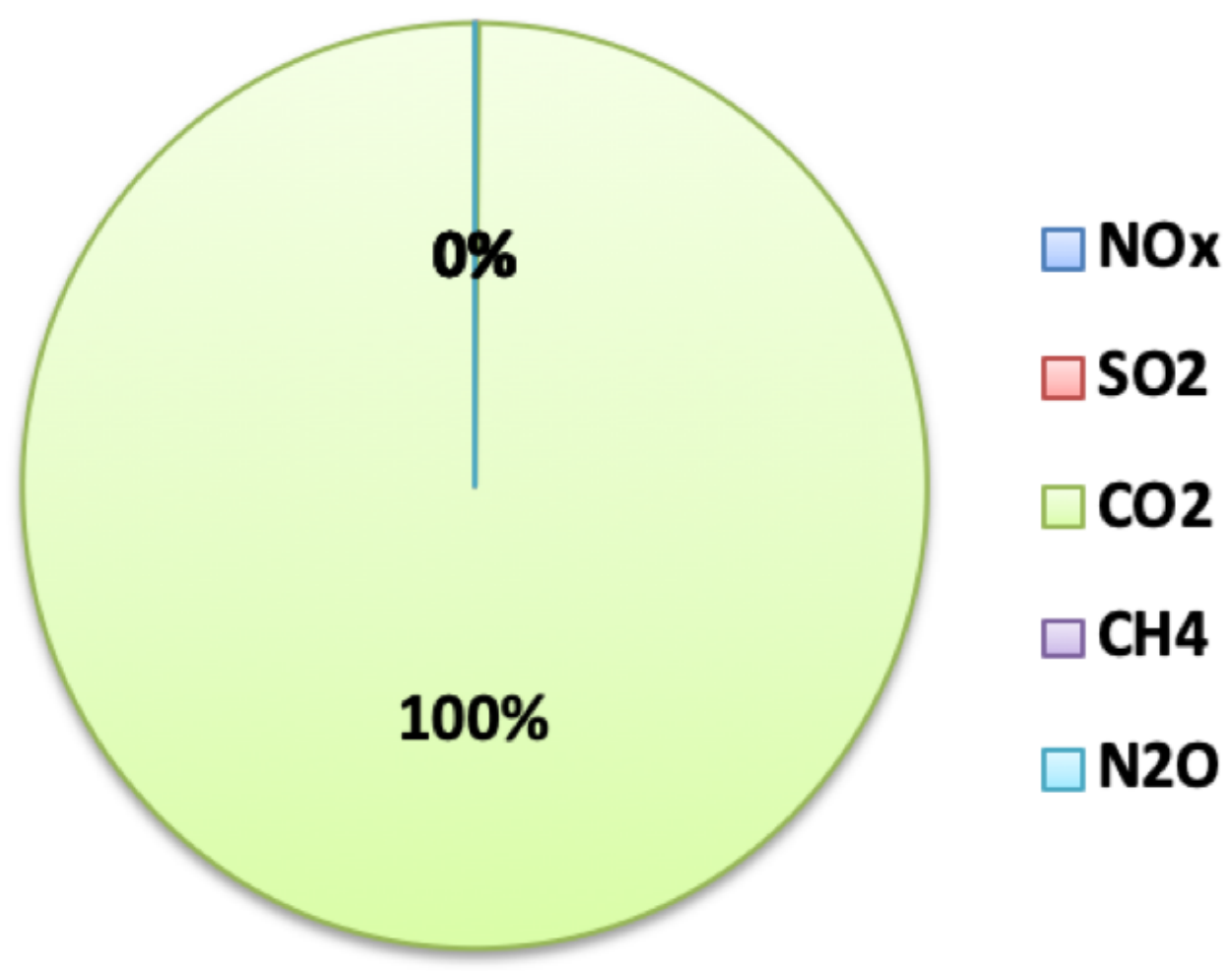

2016 U.S. Annual Net Generation (Mwh)

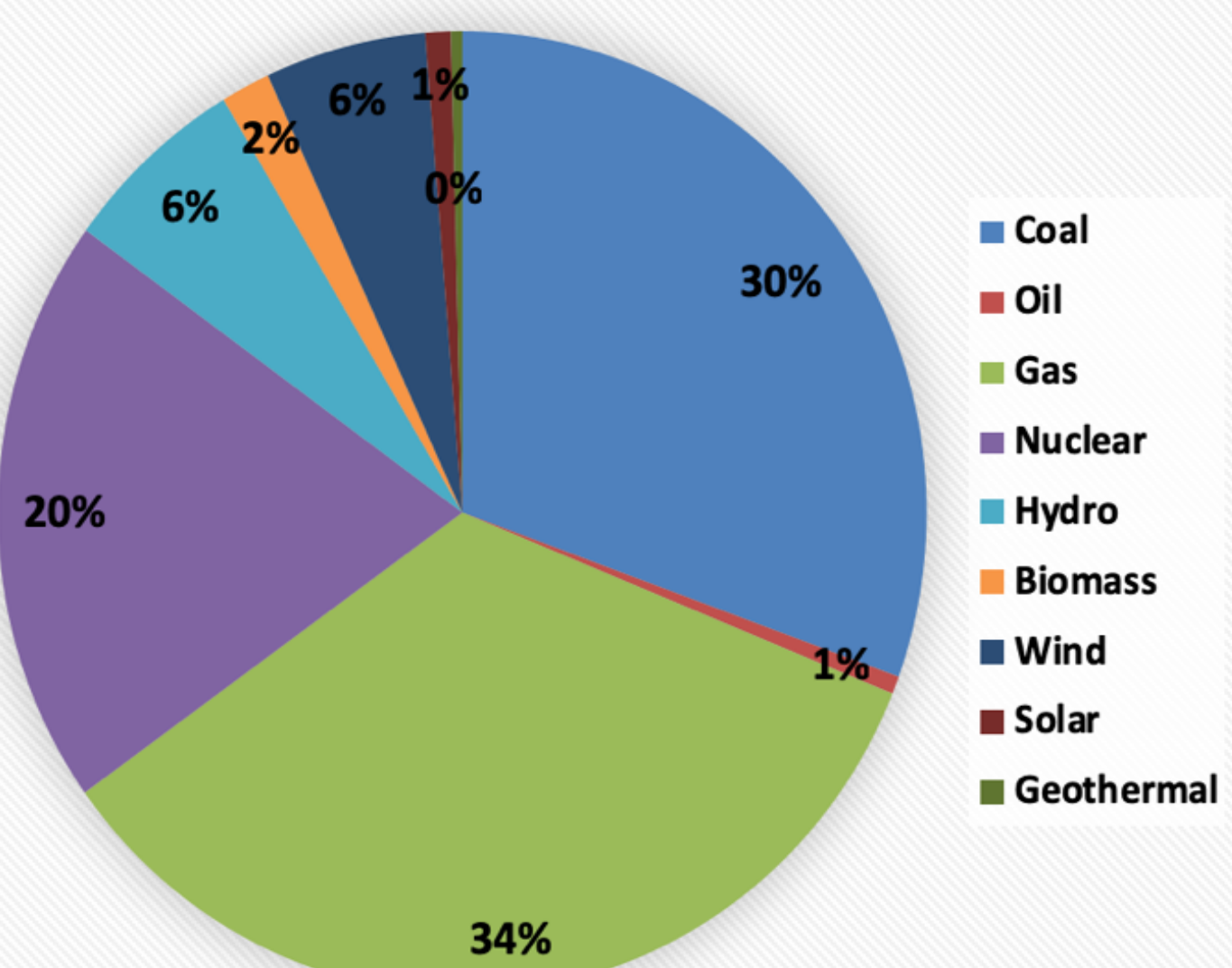

According to the EPA eGRID2016 database, as of 2016, U.S. emits about $2 \times 10^{9}$ tonnes $\mathrm{CO}_{2} /$ year as shown. Out of that North Dakota has about $37 \times 10^{6}$ tonnes $\mathrm{CO}_{2}$ /year net generation of $\mathrm{CO}_{2}$.

- Carbon storage and enhanced oil recovery are two methods which gets rocks exposed to $\mathrm{CO} 2$

- I'm studying CO2 storage effect on rock matrix, pore structures of the Bakken shale. 


\section{Introduction}
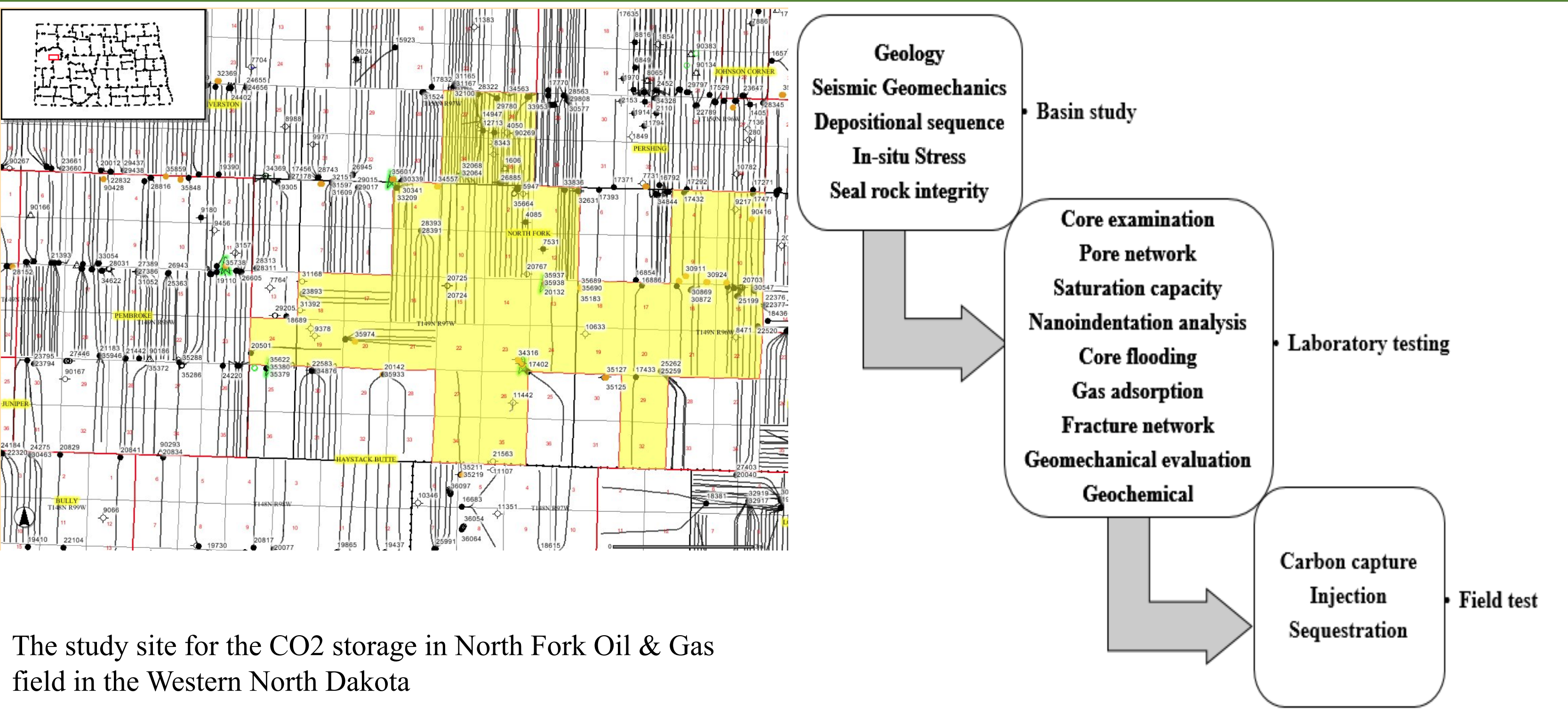

The study site for the CO2 storage in North Fork Oil \& Gas field in the Western North Dakota 


\section{Introduction}

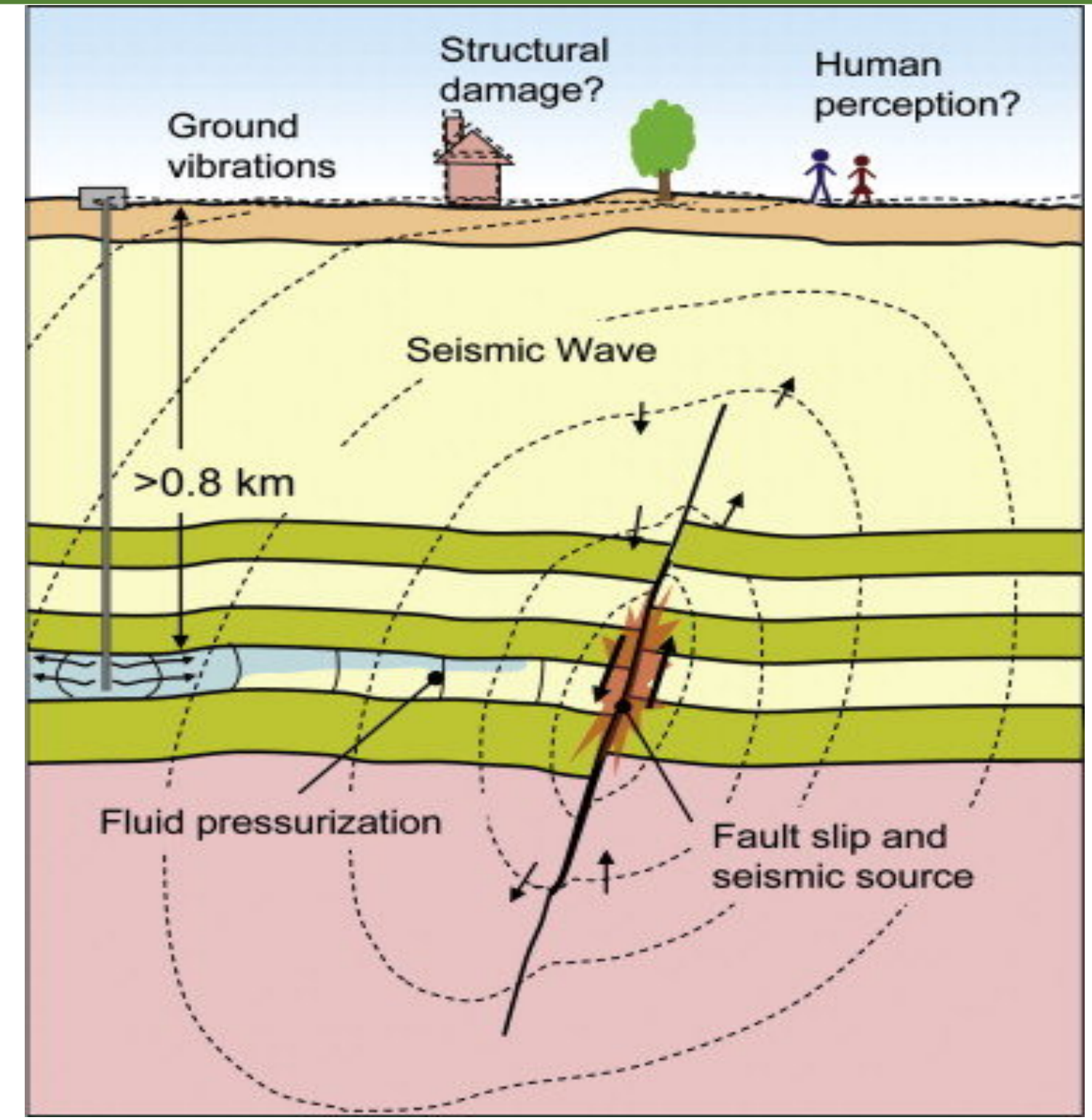

- $\mathrm{CO} 2$ operations involve the injection and pressurization of reservoirs that usually results in changes to the state of in-situ stresses that may destabilize fractures.

- Instability can lead to slippage along preexisting fracture systems.

- Fractures are conduits for fluid seepages and may raise reservoir pressures. 


\section{Introduction}

- $\mathrm{H}_{2} \mathrm{O}+\mathrm{CO}_{2} \leftrightarrow \mathrm{H}_{2} \mathrm{CO}_{3}$

- $\mathrm{CaCO}_{3}+\mathrm{H}_{2} \mathrm{CO}_{3} \leftrightarrow \mathrm{Ca}\left(\mathrm{HCO}_{3}\right)_{2}$

- When carbon dioxide is injected into shale reservoir, it dissolves in water and changes the acidbase equilibrium that then triggers the dissolution and precipitation of minerals.

- Carbon dioxide dissolves in water to form bicarbonate (Equation 1) and dissociates to carbonic acid. Carbonic acid dissolved calcites in carbonate rocks (Equation 2). 

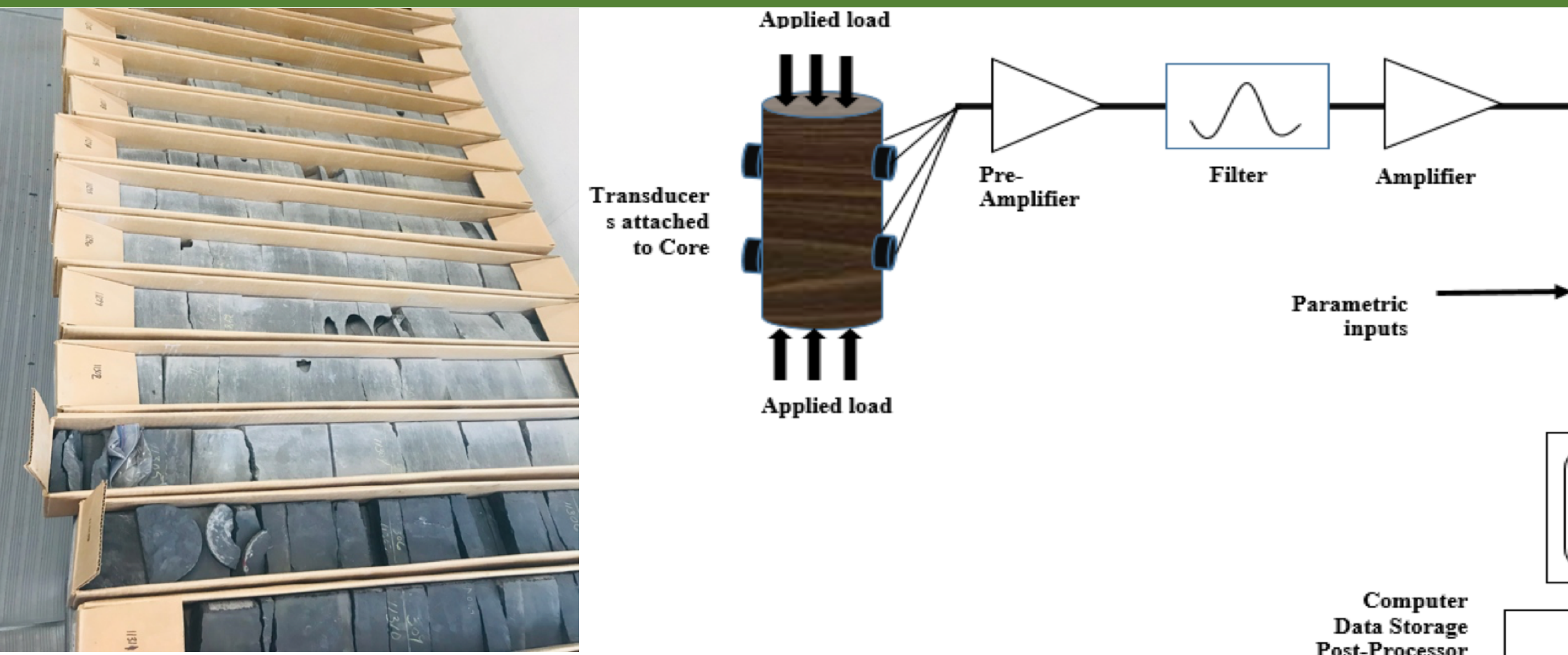

Signal

Conditioner

and

Event

Detector

Applied load

Computer

Data Storage Post-Processor

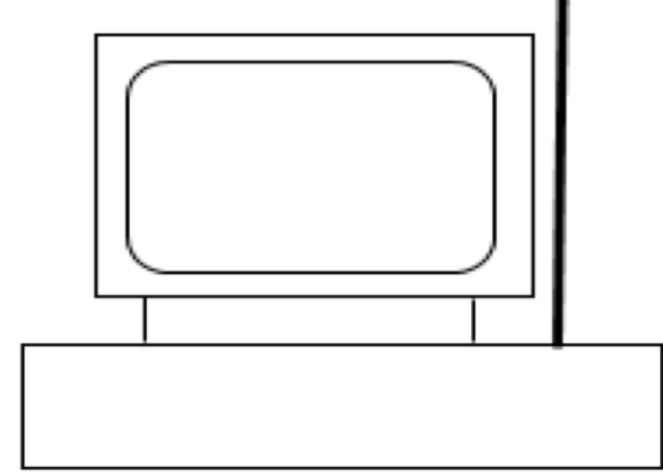

Acoustic Emission method 
Elastic Properties of Shale before and after CO2 Exposure

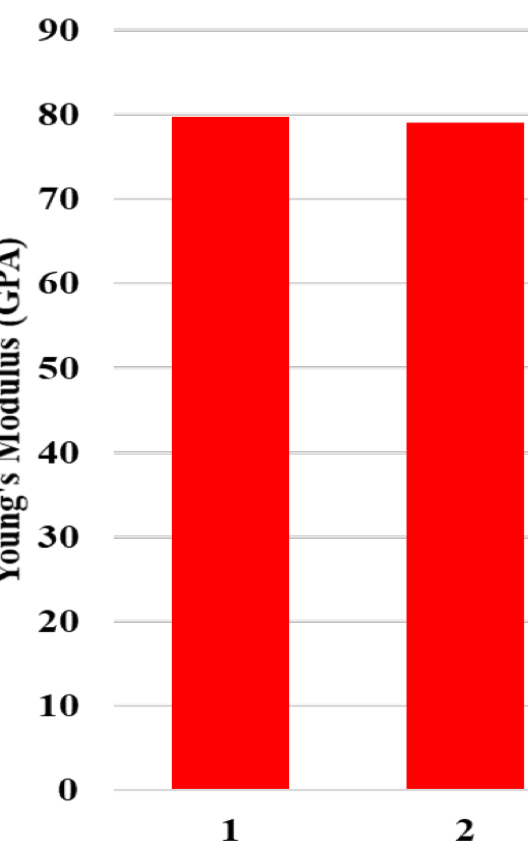

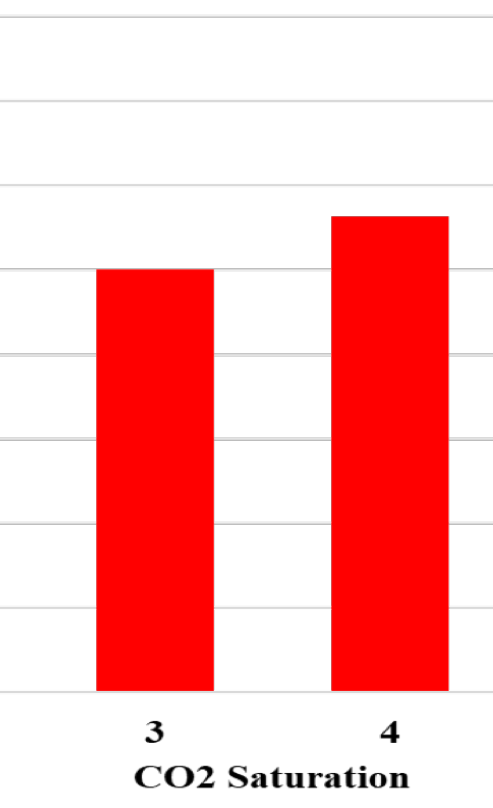
CO2 Saturation

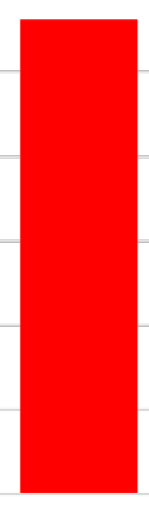

5

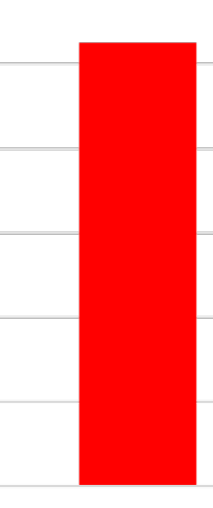

6
5

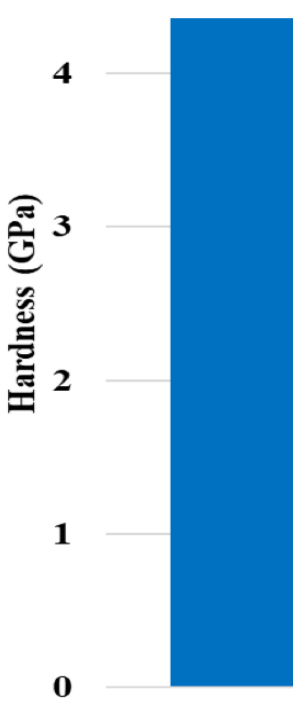

1
Elastic Properties of Shale before and after CO2 Exposure

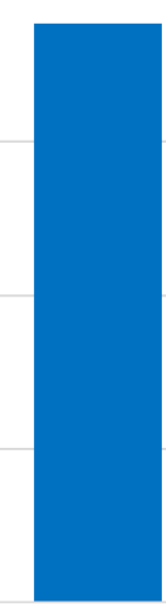

2

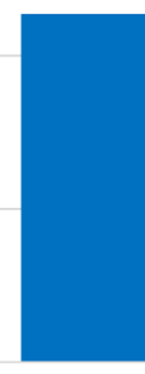

3

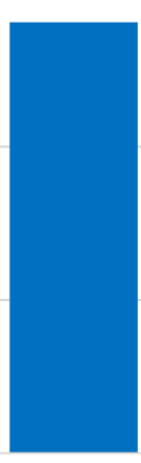

4

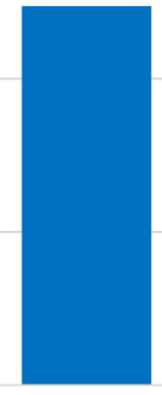

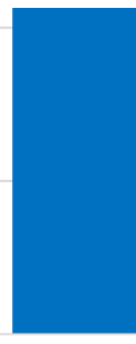

The average Young's modulus and hardness of the shale reservoir was 79.8 and $4.4 \mathrm{G}$ Pa before saturation, 52.6 and $2.1 \mathrm{G} \mathrm{Pa}$ after 60 days $\mathrm{CO} 2$ saturation. 
- The Young's modulus declined at 34\% after 60 days and the hardness declined at $51 \%$ after 60 days.

- Perform X-ray Powder Diffraction (XRD) test to estimate how the mineralogical components of the sample will change with respect to the $\mathrm{CO} 2$ exposure.

- Estimate the pore network and the pore connectivity changes using gas adsorption.

- Generate seismic of the core plug to to better understand the pore network and structure in high frequency.

- Determine the crack propagation of the shale reservoir using acoustic emission with overburden load. 


\section{Acknowledgments}
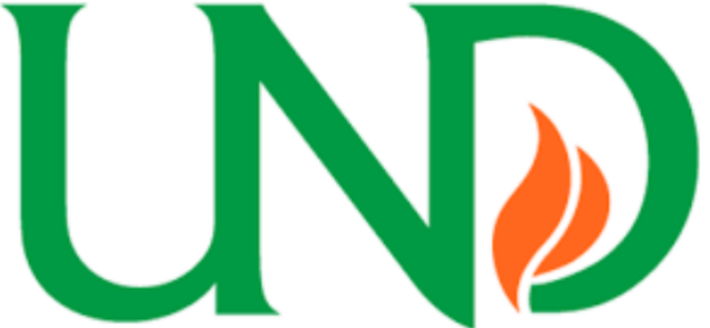

N NO'RTH

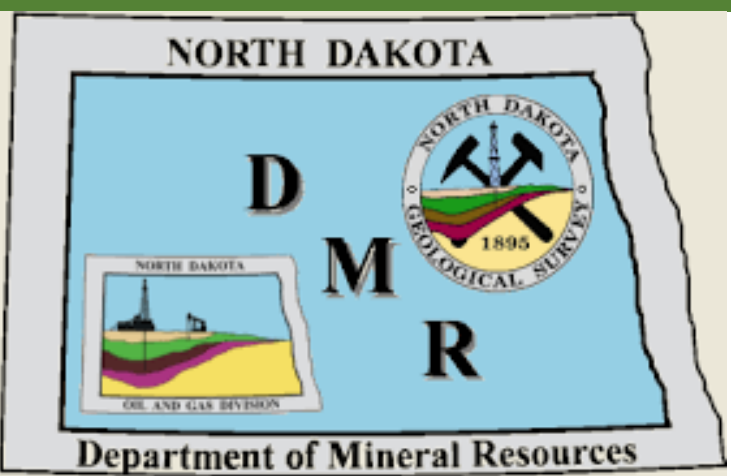

Department of Mineral Resources

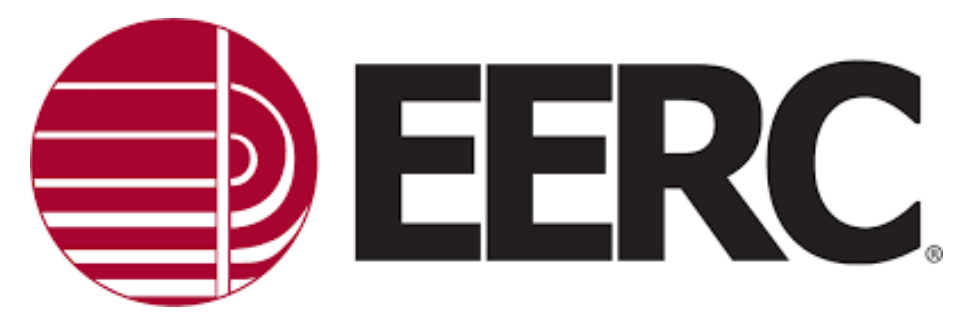

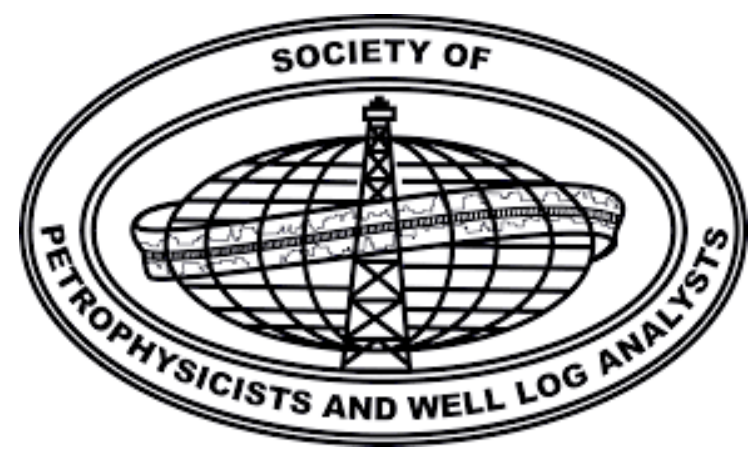

NORTH DAKOTA PETROLEUM
THE

GEOLOGICAL SOCIETY

OF AMERICA ${ }^{\circledR}$

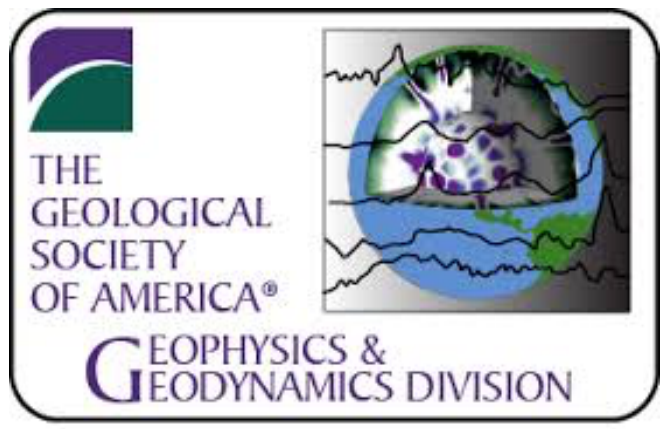


Question? 